\title{
Improved antenna phase center models for GLONASS
}

\author{
Rolf Dach • Ralf Schmid - Martin Schmitz - Daniela Thaller - Stefan Schaer • \\ Simon Lutz $\cdot$ Peter Steigenberger $\cdot$ Gerhard Wübbena $\cdot$ Gerhard Beutler
}

Received: 12 October 2009/Accepted: 27 March 2010/Published online: 11 April 2010

(C) Springer-Verlag 2010

\begin{abstract}
Thanks to the increasing number of active GLONASS satellites and the increasing number of multiGNSS tracking stations in the network of the International GNSS Service (IGS), the quality of the GLONASS orbits has become significantly better over the last few years. By the end of 2008, the orbit RMS error had reached a level of $3-4 \mathrm{~cm}$. Nevertheless, the strategy to process GLONASS observations still has deficiencies: one simplification, as applied within the IGS today, is the use of phase center models for receiver antennas for the GLONASS observations, which were derived from GPS measurements only, by ignoring the different frequency range. Geo++ $\mathrm{GmbH}$ calibrates GNSS receiver antennas using a robot in the field. This procedure yields now separate corrections for the receiver antenna phase centers for each navigation satellite system, provided its constellation is sufficiently
\end{abstract}

R. Dach $(\varangle) \cdot$ D. Thaller $\cdot$ S. Lutz · G. Beutler

Astronomical Institute, University of Bern, Sidlerstrasse 5,

3012 Bern, Switzerland

e-mail: rolf.dach@aiub.unibe.ch

R. Schmid

Forschungseinrichtung Satellitengeodäsie,

Technische Universität München, Arcisstrasse 21,

80333 Munich, Germany

M. Schmitz · G. Wübbena

Geo++ GmbH, Steinriede 8, 30827 Garbsen, Germany

S. Schaer

Swiss Federal Office of Topography swisstopo,

Seftigenstrasse 264, 3084 Wabern, Switzerland

P. Steigenberger

Institut für Astronomische und Physikalische Geodäsie,

Technische Universität München, Arcisstrasse 21,

80333 Munich, Germany populated. With a limited set of GLONASS calibrations, it is possible to assess the impact of GNSS-specific receiver antenna corrections that are ignored within the IGS so far. The antenna phase center model for the GLONASS satellites was derived in early 2006, when the multi-GNSS tracking network of the IGS was much sparser than it is today. Furthermore, many satellites of the constellation at that time have in the meantime been replaced by the latest generation of GLONASS-M satellites. For that reason, this paper also provides an update and extension of the presently used correction tables for the GLONASS satellite antenna phase centers for the current constellation of GLONASS satellites. The updated GLONASS antenna phase center model helps to improve the orbit quality.

Keywords GLONASS - Multi-GNSS processing ·

Receiver antenna $\cdot$ Satellite antenna .

Phase center modeling · Reference frame - GNSS orbits

\section{Introduction}

The Globalnaya Navigatsionnaya Sputnikovaya Sistema (GLONASS; Russian for Global Navigation Satellite System) - the Russian counterpart of the American Global Positioning System (GPS)-became important in Global Navigation Satellite System (GNSS) analyses during the last few years. Today (May 2009), 20 GLONASS satellites are active and the satellite constellation has become very stable with the second generation of GLONASS-M satellites. A number of manufacturers provide combined GPS/ GLONASS receivers. As the GPS/GLONASS tracking network of the International GNSS Service (IGS, Dow et al. 2009) reached nearly global coverage by the end of 2008 , the quality of the GLONASS orbits is now at a level of 3-4 cm. 
This accuracy level still is about three times lower than that for the GPS orbits. Dach et al. (2009) showed that the improvements due to adding GLONASS to GPS observations are limited to parameters valid for a short time span (one hour and shorter). For parameters with a longer validity interval, the uncertainty of the observation modeling absorbs the statistically expected benefit from additional measurements in the analysis model.

The currently available models for the receiver and satellite antenna phase center locations limit the achievable accuracy of GLONASS results. Both categories of antennas will be addressed subsequently, but first of all it is necessary to describe the data processing strategy used as the basis for all further experiments in "Reprocessing of GLONASS data at CODE".

No distinction is made between the GPS and GLONASS frequencies for the receiver antennas within the IGS so far. The GPS-derived corrections are used for the measurements of both GNSS. In "GNSS-specific receiver antenna phase center modeling", the differences between GNSSspecific corrections as well as their impact on coordinate estimates are analyzed.

The phase center corrections (PCC) currently used within the IGS for the GLONASS satellite antennas (igs05.atx model, Schmid et al. 2007) also have several drawbacks. They were computed in early 2006 when the GLONASS-capable receivers in the IGS network were mainly located in Europe and when the first two GLONASS-M satellites were in space only for a short time span. Since then almost all GLONASS satellites have been replaced by new generation satellites. Both the number and the global distribution of GLONASS tracking stations have been improved significantly since 2006. The number of different antenna types has also grown significantly. These developments indicate that an update of the satellite antenna phase center models for the GLONASS satellites is badly needed. "Satellite antenna phase center modeling" describes the generation of such models.

The updated receiver and satellite antenna phase center models are validated in "Validation of the satellite antenna phase center models".

\section{Reprocessing of GLONASS data at CODE}

CODE, the Center for Orbit Determination in Europe, is a joint venture of the Astronomical Institute of the University of Bern (AIUB, Bern, Switzerland), the Swiss Federal Office of Topography (swisstopo, Wabern, Switzerland), the Federal Agency for Carthography and Geodesy (BKG, Frankfurt am Main, Germany), and the Institut für Astronomische und Physikalische Geodäsie of the Technische Universität München (IAPG/TUM, Munich, Germany).
CODE has been one of the global analysis centers of the IGS since the start of IGS test campaign operations on June 21, 1992. All operational computations are performed at the AIUB using the development version of the Bernese GPS Software (Dach et al. 2007). Since May 2003, CODE has been analyzing GPS and GLONASS data in a combined analysis to achieve the best possible consistency of the GPS and GLONASS orbit products. This strategy is not only applied to the CODE contributions to the IGS final products, but also to its rapid and ultra-rapid products.

CODE also participates in the first reprocessing campaign of the IGS. The IGS decided to limit this activity to a GPS-only solution. The corresponding computations of CODE were performed at IAPG/TUM between summer 2008 and spring 2009 (Steigenberger et al. 2009). The processing strategy of the operational CODE solution from August 2008 was used for this effort (except that the reprocessing was limited to GPS). In this way, a consistent time series of GPS-derived CODE products from January 1994 up to December 2008 could be generated.

The reprocessed GPS-only products were extended to GLONASS by introducing GLONASS tracking data gathered after May 2003 in addition to the GPS data. The GPS/ GLONASS tracking data were processed using the strategy applied to the IGS reprocessing. Finally, the additional observations were combined with the GPS-only part on the observation level to generate a fully consistent multisystem time series of products.

For the GLONASS extension of the reprocessed solutions, more GLONASS tracking stations could be included than in the operational processing (Fig. 1). Even though most of the stations were still located in Europe (at least till the end of 2007), the quality of the GLONASS orbits could be improved by a factor of about two. It reached a level of about 5-6 cm at the end of 2007 and improved to $3-4 \mathrm{~cm}$ by the end of 2008 (Fig. 2). For comparison, the corresponding values for the GPS satellites are $1-2 \mathrm{~cm}$. This quality measure is based on an orbit determination process: apart from the six initial osculating orbital elements, nine empirical parameters in the Sun-oriented coordinate system at the satellite consisting of a component $(D)$ pointing from the satellite to the Sun, of a $(Y)$ component along the solar panel axis of the satellite, and the $(X)$ component completing the right-hand system (three constant and six once-per-revolution parameters, Beutler et al. 1994) were determined introducing the satellite positions every $15 \mathrm{~min}$ from three independent consecutive daily solutions.

\section{GNSS-specific receiver antenna phase center modeling}

The PCC model, as it is used within the IGS consists of two components. The so-called phase center offset (PCO) is a 
Fig. 1 Number of sites in the IGS network providing GLONASS data, which were used for orbit determination in the CODE operational (blue) and reprocessed (red) solutions
Fig. 2 Median of the RMS for the fit of a 3-day arc of the operational (blue) and reprocessed (red) CODE orbits for the GLONASS satellites as well as of the operational GPS orbits (green)
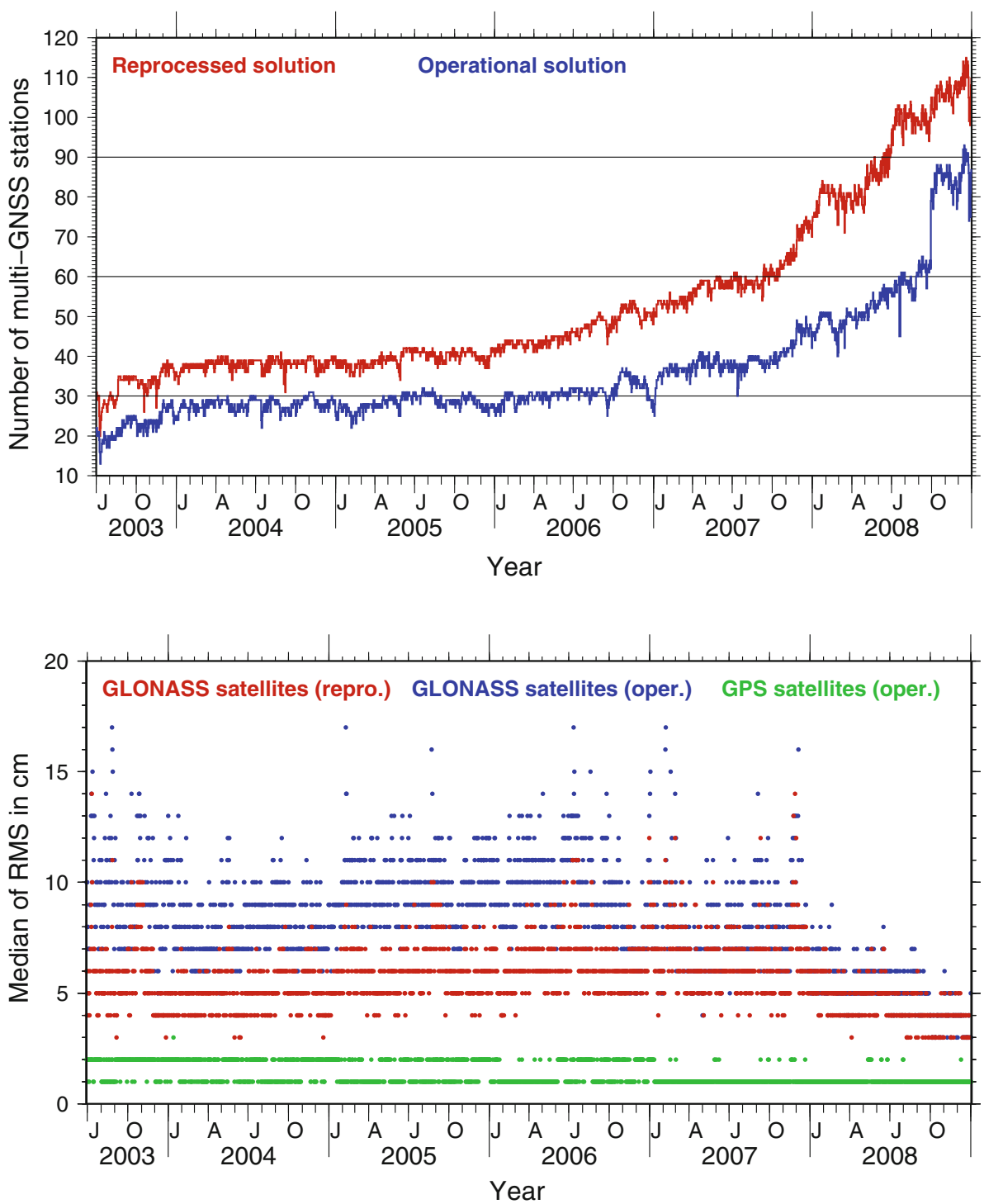

vector pointing from a mechanical marker at the antenna (antenna reference point) to a mean phase center. Additional azimuth- and elevation-dependent phase center variations (PCV) are usually provided in grids. Any change in the PCO can be compensated by the PCV. In consequence, the PCO can be freely defined (e.g., to have no $\mathrm{PCV}$ correction in zenith direction) as long as the PCV are consistently used.

Update of the igs05.atx phase center model

The set of antenna PCC (contained in the file igs05.atx, maintained by the IGS) currently used by the IGS was compiled in 2005/06 when the absolute antenna phase center model was introduced (Schmid et al. 2007). According to the rules for the maintenance of that file (IGS Mail No. 5440 and General antenna file information of the antenna calibration working group of the IGS, available at
ftp://ftp.igs.org/pub/station/general/antenna_README.pdf) generally only new antenna/radome combinations are added. Therefore, many corrections are up to 4 years old. Many additional antennas were calibrated since that time, which could help to improve the "type-mean" corrections of the corresponding antenna types. The calibration values contained in igs05.atx are based on GPS measurements only. GLONASS observations were not included due to the weak GLONASS constellation at that time. This is why the GPS-derived antenna PCC are also used for the GLONASS observations made on different frequencies.

More GLONASS satellites are active today than in 2005/06. Therefore, system-specific corrections for GPS and GLONASS can be determined using a robot (Wübbena et al. 2006). Table 1 lists all antenna/radome combinations contained in the reprocessed network, for which GNSSspecific PCC were available. The calibration values resulted in an updated version of igs05.atx, called from now on 


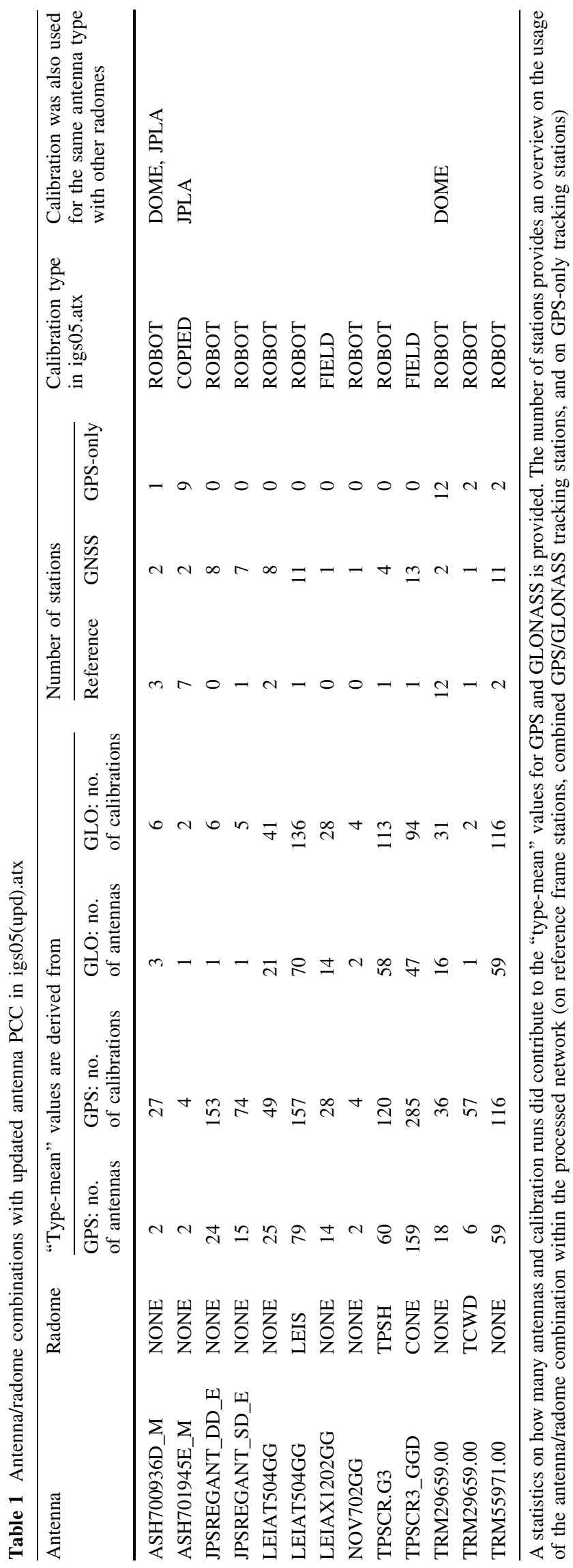

igs05(upd).atx, which was used for this study. Note that the new calibration values for GPS replace the existing values in the IGS file igs05.atx.

As a consequence, all reference frame stations using one of these antenna types have to be excluded from the datum definition because an offset in the estimated station coordinates is expected ("Use of GNSS-specific PCC"). Therefore, 35 out of 96 IGS reference frame sites were omitted for the datum definition. This results in a dilemma: one would like to have the most recent antenna PCC tables with as many individual calibrations for the "type-mean" values as possible, and one would like to maintain a stable geodetic reference frame at the same time.

The number of individual antennas and calibration runs used to obtain the updated GPS-specific antenna "typemean" corrections for igs05(upd).atx reveals a strong imbalance between the different antenna/radome combinations (Table 1). The "type-mean" values for the Ashtech and NovAtel antennas are both based on only two individual antennas. Thus, the redundancy is small. Fortunately, these antenna types did not find widespread use in the IGS network (except for ASH701945E_M NONE). Therefore, it is expected this problem to have only marginal impact on the general results of this study.

There are several antennas with a limited number of individual antennas contributing to the GLONASS-specific antenna "type-mean" PCC (Table 1). The conclusions emerging from this study may be in particular problematic for the two Javad Regant types, because they dominated the GLONASS tracking network prior to 2006 (about onethird of the network was equipped with this combination).

Figure 3 (top), showing the number of stations in the reprocessed GLONASS tracking network of December 2003 equipped with a specific antenna/radome combination, illustrates the situation. About $50 \%$ of the stations are equipped with antenna types for which robot calibrations are available (for the original igs05.atx model before the update the percentage is only 40\%). igs05(upd).atx includes GLONASS-specific antenna PCC for about half of the stations (indicated by red-labeled antenna names in Fig. 3). This situation is more or less stable till the second half of 2006.

Figure 3 (bottom) illustrates the situation in December 2008, which is very close to the current state of the GLONASS tracking network used in the operational CODE processing. Note that there are new antenna types (in particular from Trimble and Leica) dominating the network. Most of these antenna types were calibrated with a robot. By updating the robot calibrations from igs05.atx to igs05(upd).atx, the percentage of receiver/antenna combinations with a robot calibration grows from 59 to $72 \%$. About two-thirds of the GLONASS tracking stations available in December 2008 can be processed with 
Fig. 3 Number of combined GPS/GLONASS tracking stations in the processed network equipped with a specific antenna/radome combination (top average over all days in December 2003, bottom average over all days in December 2008). The colors characterize the calibration types (see ANTEX format description at ftp://ftp.igs.org/pub/station/ general/antex13.txt). The percentage of the different calibration types is given in the legend for igs05(upd).atx and in parentheses for the original igs05.atx model. Antenna types with red labels got updated PCC in igs05(upd).atx

$$
\begin{aligned}
& \text { ASH7 01945C_M } \\
& \text { AOAD/M_T } \\
& \text { ASH7 01073.1 } \\
& \text { TRM2 9659.00 } \\
& \text { ASH701073.3 } \\
& \text { AOAD/M_B } \\
& \text { AOAD/M_T } \\
& \text { ASH7 0 0936D_M } \\
& \text { ASH7 01073.1 } \\
& \text { ASH701073.1 } \\
& \text { ASH7 01941.1 } \\
& \text { ASH7 01941.B } \\
& \text { ASH701946.2 } \\
& \text { ASH701946.3 } \\
& \text { ASH701073.1 } \\
& \text { ASH7 01941.B } \\
& \text { TPSCR3_GGD } \\
& \text { AOAD/M_T } \\
& \text { JPSREGANT_DD_E } \\
& \text { JPSREGANT_SD_E }
\end{aligned}
$$

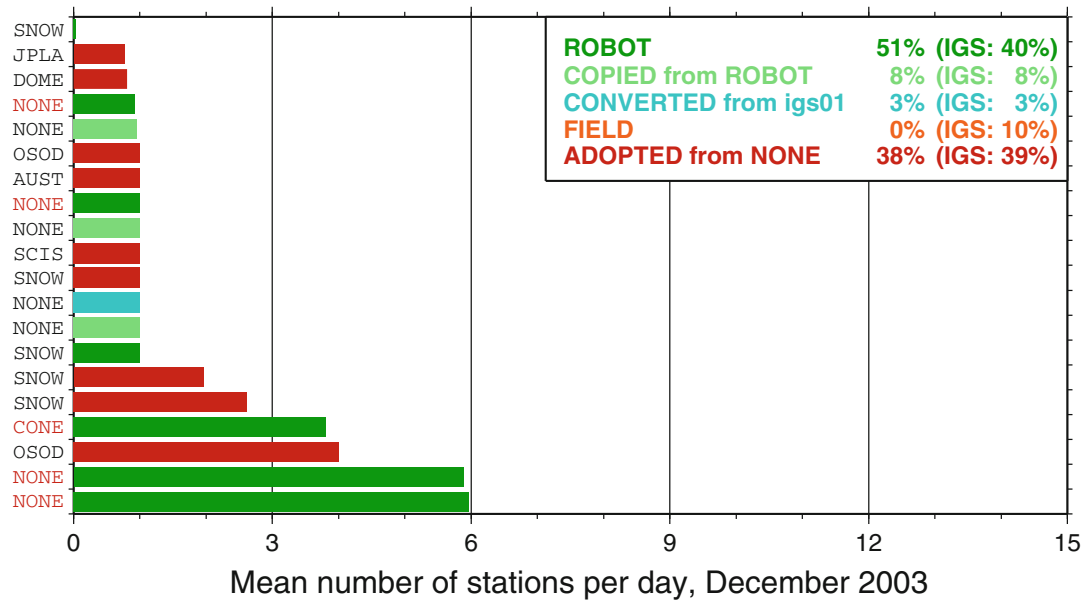

TRM29659.00 AOAD/M_B JPLD/M_R A.SH7 01073.1 A.SH7 01945G_M LEIAT504 ASH700936D M LEIAR2 5 ASH7 01946.3 TRM29659.00 AOAD/M_B $\mathrm{AOAD} / \mathrm{M}$ - T $\mathrm{AOAD} / \mathrm{M}$ ASH7 00936C_M A.SH7 01073.1 ASH701073.1 ASH7 01941.B ASH7 01945B_M ASH7 01945C_M TPSCR.G3 TPSCR3_GGD TPSG3 A1 TRM57971.00 AOAD/M_T ASH7 01945E_M NOV702GG ASH701941.B LEIAX1202GG $\mathrm{AOAD} / \mathrm{M} \_\mathrm{T}$ JPSREGANT_SD_E TRM29659.00 TPSCR3_GGD $\mathrm{AOAD} / \mathrm{M} \mathrm{T}$ ASH7 01945C_M JPSREGANT DD TPSCR3_GGD LEIAT $504 \mathrm{GG}$ LEIAT $504 \mathrm{GG}$ TRM55971.00

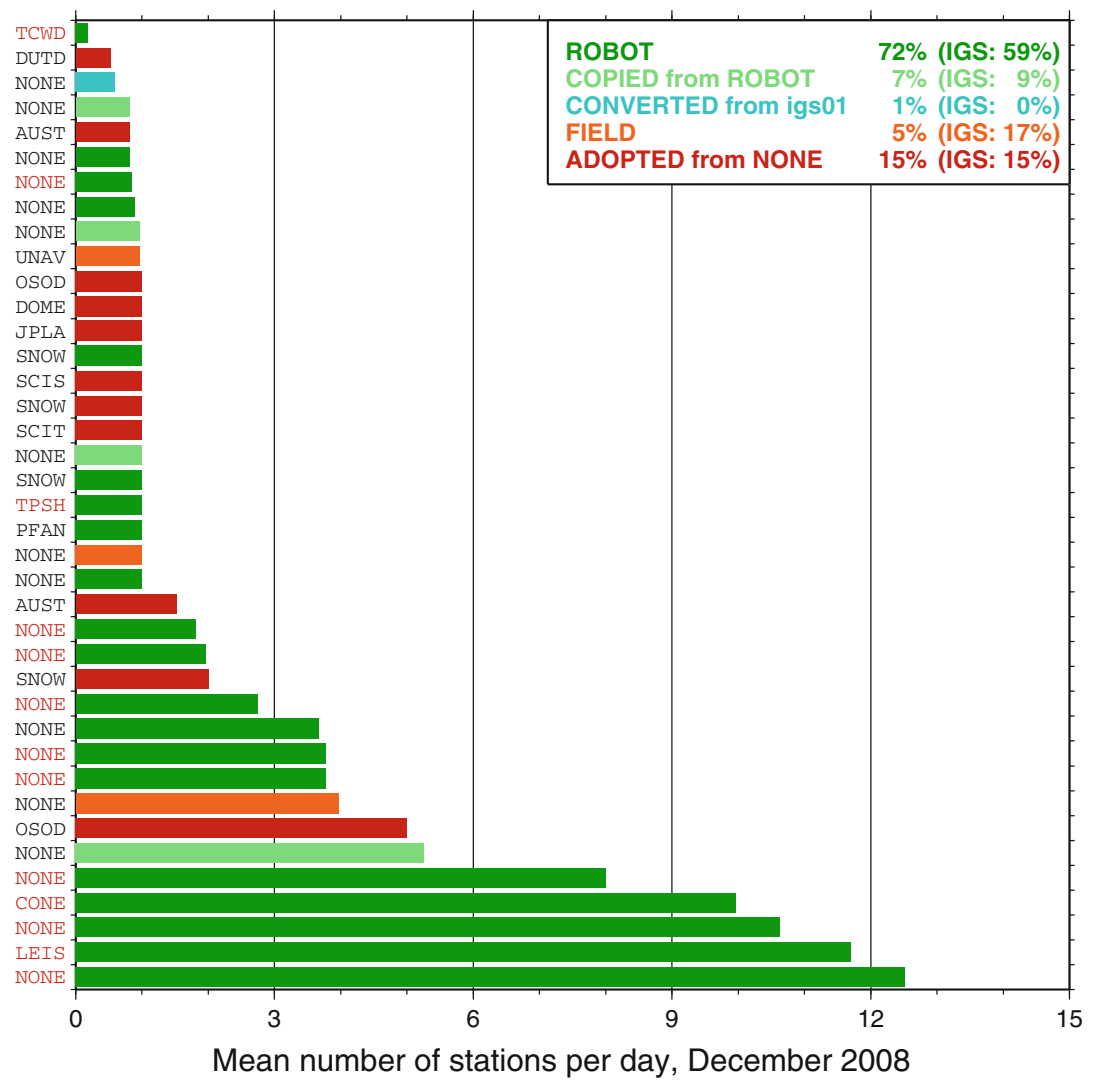

GNSS-specific antenna PCC in this study (red labels in Fig. 3, bottom).

\section{Use of GNSS-specific PCC}

Before studying the impact of GNSS-specific antenna PCC, it is possible to check the impact of the updated GPS corrections on the resulting station coordinates. Coordinate estimates from a solution using the original igs05.atx antenna PCC tables are compared with a solution using the updated igs05(upd).atx values. In both cases, the GPSderived corrections are used for the GPS and GLONASS measurements. The differences in the up component are shown in Fig. 4. They reach values of up to $5 \mathrm{~mm}$, even though both solutions use the same set of reference stations for the no-net-rotation (NNR) condition in a minimum constraint solution for the datum definition. As expected, the differences show systematics for the individual antenna types, regardless of whether the antenna was used at a GPS-only or a combined GPS/GLONASS tracking station (dark blue and red bars). Surprisingly, there are also a few stations that show differences of $>1 \mathrm{~mm}$, although the same antenna PCC are used in both computations (light blue and red bars). Most of these stations only observed for 


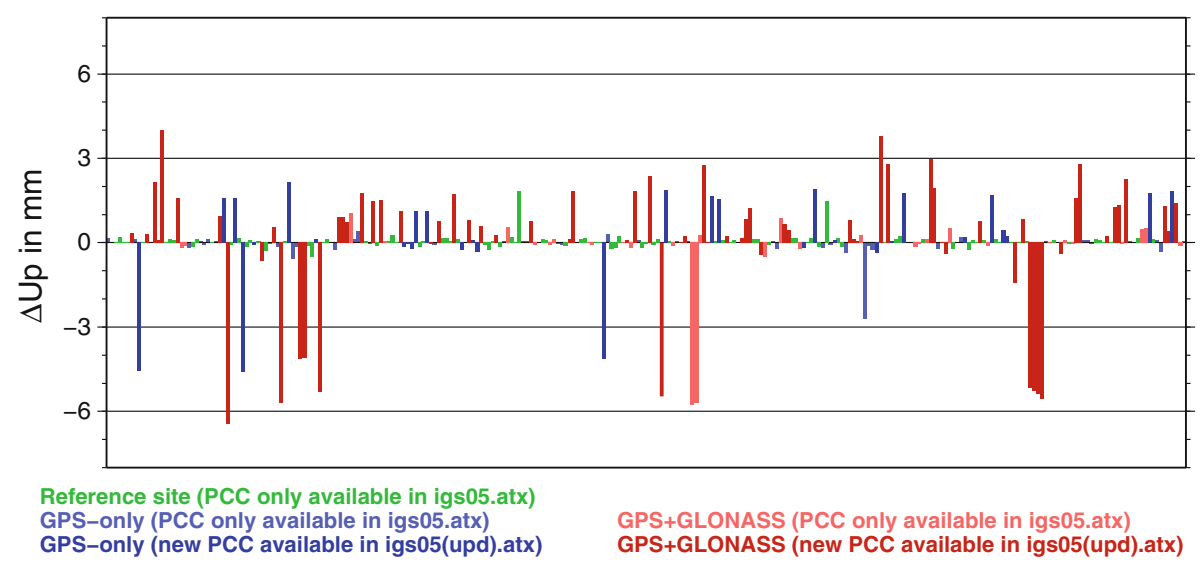

Fig. 4 Differences of the station heights between solutions using the original igs05.atx and the updated igs05(upd).atx antenna PCC. The GPS-derived corrections are used for the GPS and the GLONASS measurements. The stations are sorted alphabetically, but they are not

labeled. Both coordinate sets are computed from the entire interval of 6.5 years of the GLONASS extension of the CODE reprocessing as described in "Reprocessing of GLONASS data at CODE"

a limited number of days within the entire period of 6.5 years.

The differences between the elevation- and azimuthdependent PCV for the GPS and GLONASS frequencies are in the range of a few $\mathrm{mm}$ for $\mathrm{L} 1$ and $\mathrm{L} 2$, respectively. According to Wübbena et al. (2006), these values are reproducible to within $0.3-0.4 \mathrm{~mm}$. The differences between individual antennas of the same type have absolute values in the range of $2-3 \mathrm{~mm}$ for low elevations. Thus, the differences between GNSS-specific antenna PCC are significant, at least for those with a "type-mean" value derived from a suitable number of individual antennas.

When converting the elevation- and azimuth-dependent PCV for the L1 and L2 frequencies into the ionosphere-free linear combination (as they are needed for a global network analysis), the differences between the GPS- and GLONASSspecific corrections may reach $10 \mathrm{~mm}$ in absolute value. The differences for one of the Ashtech antennas are shown as a typical example in Fig. 5. Note that the mean difference between the GPS- and GLONASS-specific PCV corresponds to a time bias between the GPS and GLONASS measurements. Thus, it is absorbed by the inter-system bias, which has to be taken into account in the multi-GNSS processing for each station at least as a constant bias between the receiver hardware delays of the individual GNSS.

In order to analyze the impact of the GNSS-specific antenna PCC on the mean station coordinates, the entire interval of the GLONASS extension of the CODE reprocessing (6.5 years) has been analyzed with the updated antenna PCC table. In a first run, the GPS-derived corrections were used for both GPS and GLONASS measurements, whereas in the second run the GNSS-specific corrections were used. Two cumulative solutions have been derived considering mean station coordinates and velocities. The resulting time series of station positions have been

analyzed with FODITS, a new component of the Bernese GPS Software. FODITS stands for "Find Outliers and Discontinuities in Time Series" (Ostini et al. 2008). The new tool was used to detect outliers and significant discontinuities in the station coordinate time series. The differences between the two coordinate sets (introducing identical outlier and discontinuity definition) in the vertical component are provided in Fig. 6. They are very small and reach values of $1 \mathrm{~mm}$ at maximum. These differences show, not unexpectedly, systematic effects as a function of the antenna type.

The small absolute value of the differences is surprising in view of the fact that the differences between GLONASSand GPS-specific PCV (as, e.g., shown in Fig. 5) are about twice as large as the PCV differences causing the coordinate differences in Fig. 4. It was already mentioned that the average of the difference between GNSS-specific antenna PCC is absorbed by the inter-system bias. There are, however, several other reasons for the marginal impact of GNSS-specific PCC on the estimated station coordinates:

1. The GLONASS constellation consists only of half of the number of satellites in the GPS constellation during the analyzed time span (slowly increasing to about two-thirds toward the end of 2008).

2. A much smaller number of GLONASS ambiguities were resolved than in the case of GPS, because ambiguity resolution for GLONASS was only enabled for baselines shorter than $20 \mathrm{~km}$.

3. Schaer et al. (2009) found evidence that the inter-system biases between GPS and GLONASS significantly deviate from a constant. As the current multi-GNSS processing usually implies this behavior, the solution cannot benefit in an optimal way from the additional measurements. 

PCV for GLONASS and GPS from GNSS-specific calibrations as a function of azimuth and elevation for the ASH701945E_M NONE (the antenna phase center offset is identical for both GNSS). The influence on the ionosphere-free linear combination is shown
Fig. 5 Differences between the

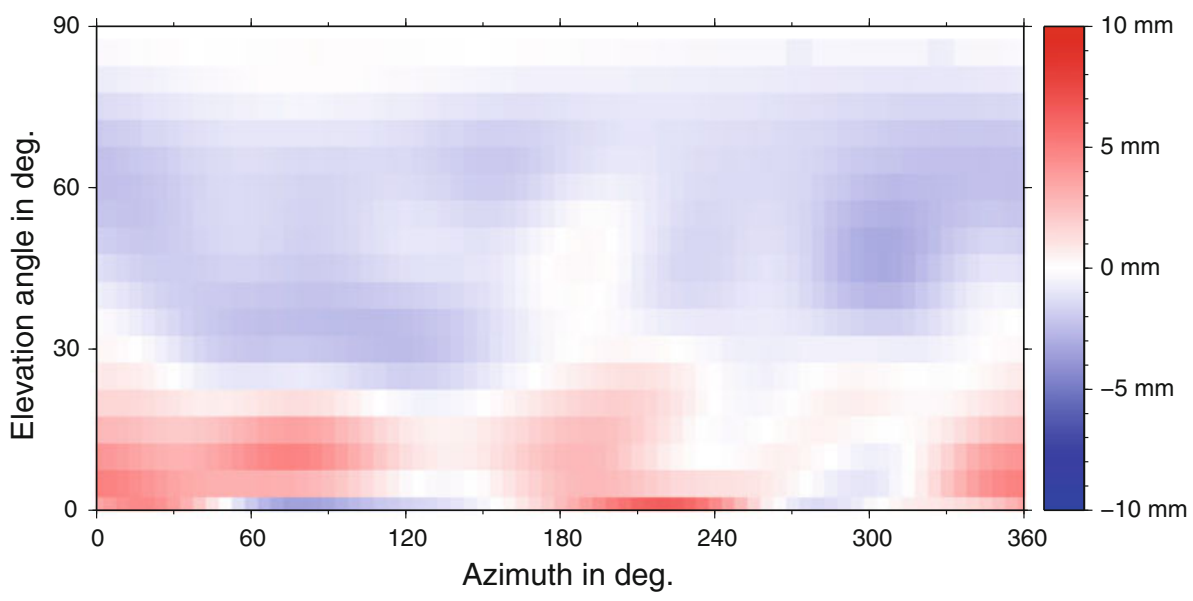

Fig. 6 Differences of the station heights between solutions considering and ignoring GLONASS-specific PCC, respectively. Both coordinate sets are computed from the entire interval of 6.5 years of the GLONASS extension of the CODE reprocessing. (Same scale as in Fig. 4 has been used for comparison.)

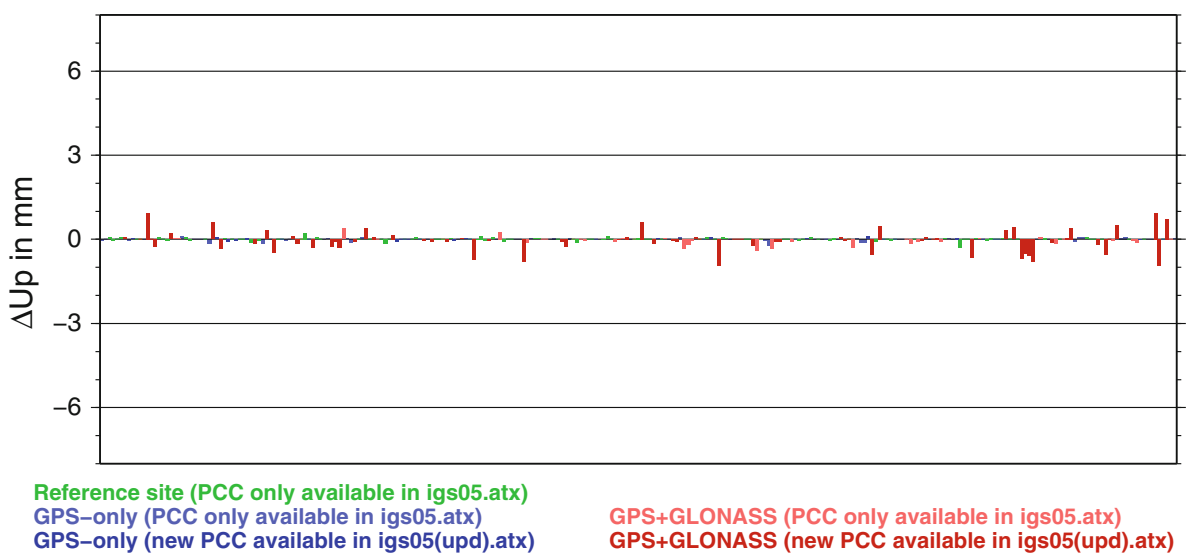

These reasons might explain why the averaged station coordinates are so clearly dominated by GPS.

In view of the sizable differences between GPS- and GLONASS-specific antenna PCC and of the continuously increasing number of available GLONASS satellites, which enhances the impact of GLONASS on the combined solution, GNSS-specific antenna PCC should be applied whenever processing multi-GNSS data sets.

\section{Satellite antenna phase center modeling}

The currently used igs05.atx model includes in addition to the receiver antenna calibrations consistent corrections for the satellite antennas. The nadir-dependent corrections for the satellite antenna phase center are mean values for all satellites of the same type (no azimuth-dependence has been considered so far). The PCO are provided individually for each satellite. The values in igs05.atx were determined in 2005 and in early 2006 (Schmid et al. 2007).

Block mean values were defined and used for the satellites launched since that time. The following GPS satellites are affected:
SVN52/PRN G31 (launched on September 25, 2006), SVN58/PRN G12 (November 17, 2006), SVN55/PRN G15 (October 17, 2007), SVN57/PRN G29 (December 20, 2007), and SVN48/PRN G07 (March 15, 2008)

(Satellites launched after December 2008 are not included because the computations for this paper were started in early 2009).

This number of satellites corresponds to about $16 \%$ of the entire constellation of 32 GPS satellites in May 2009.

The situation is even more dramatic for the GLONASS satellites. Due to the short lifetime of the older GLONASS satellites, in May 2009 there is an almost completely new GLONASS constellation compared to 2005/06 (only three satellites from end of 2005 are still active in May 2009, namely SVNs701, 712, and 795, see Fig. 7). An update of the satellite antenna phase center model, at least for these newly launched satellites, is therefore badly needed. The following sections discuss the process of updating the satellite antenna phase center model for all GLONASS and for the youngest GPS satellites. 
Fig. 7 Development of the GLONASS constellation since June 2003 until end of 2008 (a satellite is indicated as active as soon as an orbit determination was possible in the operational CODE final solution). The blue bars indicate the old style GLONASS satellites whereas red bars are used for the modernized GLONASS-M satellites. SVN711 is a prototype of the GLONASS-M series

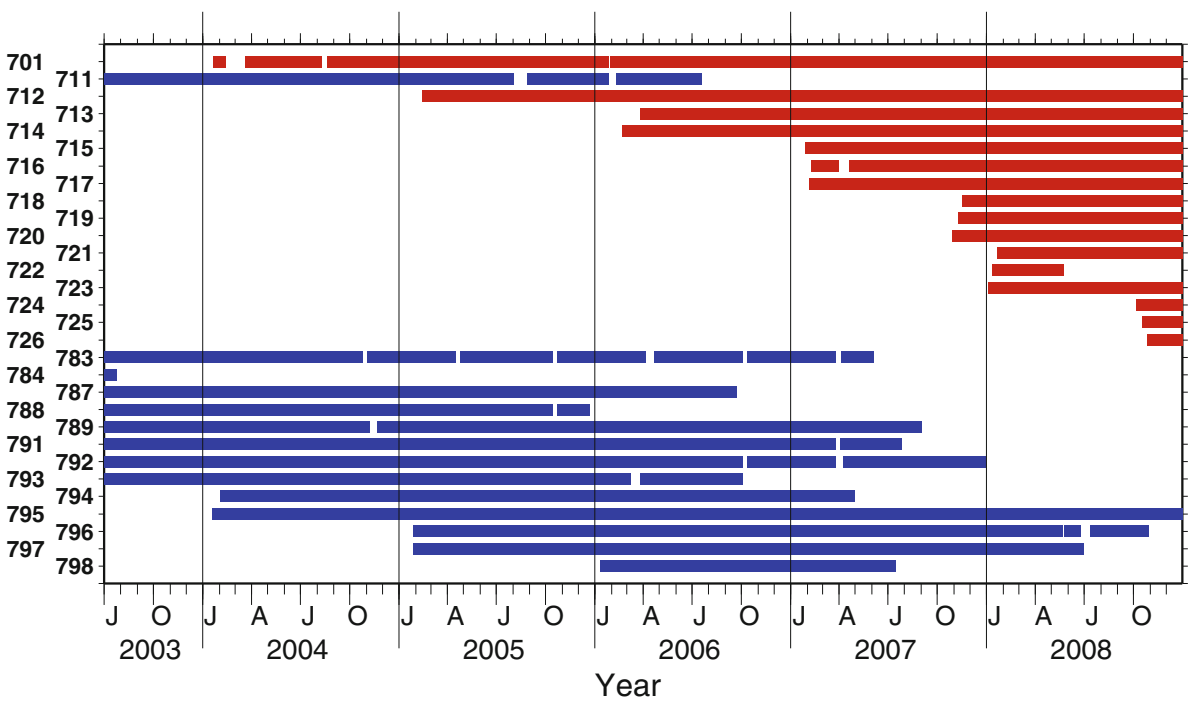

Computation of the satellite antenna model update

The satellite antenna PCC were derived from the GLONASS extension of the CODE reprocessing. From the independent 1-day solutions, 3-day solutions were derived by combining the three corresponding 1-day normal equations. As the number of orbit parameters is comparable in the 1- and 3-day orbits, the 3-day orbits are much better defined than the 1-day orbits. This is in particular true for those GLONASS satellites, which were observed mainly over Europe. The step from the 1-day to the 3-day orbits is essential, because the orbit parameters and the satellite antenna PCC are highly correlated. Six initial osculating orbital elements and nine empirical parameters (three constant and six once-per-revolution parameters in $D$-, $Y$-, and $X$-directions according to the orbit model described in Beutler et al. 1994) are set up for each satellite arc, where the periodic terms of the $D$ - and $Y$-components are constrained to zero. Empirical velocity changes (so-called pseudo-stochastic pulses) are set up and solved for at 12-h intervals.

The 3-day solutions $(>2,000)$ were then combined to generate a cumulative solution. Again FODITS was used to detect outliers and significant discontinuities in the station coordinate time series. The reference frame was aligned with the ITRF2005 using stations provided in the IGS05 (an IGS-specific realization of ITRF2005; Altamimi et al. 2007) together with NNR conditions applied to a minimum constraint solution. The station coordinates and velocities resulting from this step were introduced as known when computing the satellite antenna PCC. The igs05.atx values for all satellite antennas were kept fixed for datum definition. Different sets of coordinates and velocities were computed using the different scenarios for handling the receiver antenna $\mathrm{PCC}$, but using the same set of reference stations together with the same list of outliers and discontinuities.

Update of the satellite antenna PCO

To keep the updated satellite antenna model consistent (in scale) with igs05.atx, the PCO of the GPS satellites launched before 2005 were fixed to their igs05.atx values. Only the $Z$-offsets for the five new GPS satellites (see to the introduction to this section) and for the GPS satellite SVN53, PRN G17 (launched on September 26, 2005) were estimated, because no or only a very limited amount of data contributed to the igs05.atx values for these satellites. The $Z$-offsets for all GLONASS satellites were recomputed because of the high uncertainty of these values in igs05.atx, which was caused by the sparse GLONASS network of about 30 stations (located moreover mainly in Europe at that time).

The time series of estimates for the satellite antenna PCO (Z-component) from the 3-day solutions with respect to the corresponding igs05.atx value is shown for one of the GLONASS satellites (SVN791, PRN R22) in Fig. 8. The shaded areas indicate the eclipse periods. A correlation between the noise pattern of the estimated antenna PCO and the eclipse periods is clearly visible. This observation indicates that the Z-offset is correlated with the orientation of the orbital plane with respect to the Sun, which in turn influences the correlation between the Z-offset and the radiation pressure parameters. The noise of the $Z$-offsets increases toward the end of the time series, when the satellite was no longer reliably tracked by the stations.

The mean satellite antenna PCO computed from this time series is also plotted in Fig. 8. Three options for handling the receiver antenna PCC (mainly for the GLONASS observations) were used for comparison purposes: 
Fig. 8 Differences between satellite antenna phase center Z-offset for GLONASS satellite SVN791 (PRN R22) from 3-day solutions of the GLONASS extension of the CODE reprocessing and the values in igs05.atx. The shaded periods indicate the eclipse periods. The dashed lines indicate the mean values of the three scenarios for handling the receiver antenna PCC, see text (note, the green line is located behind the blue one)

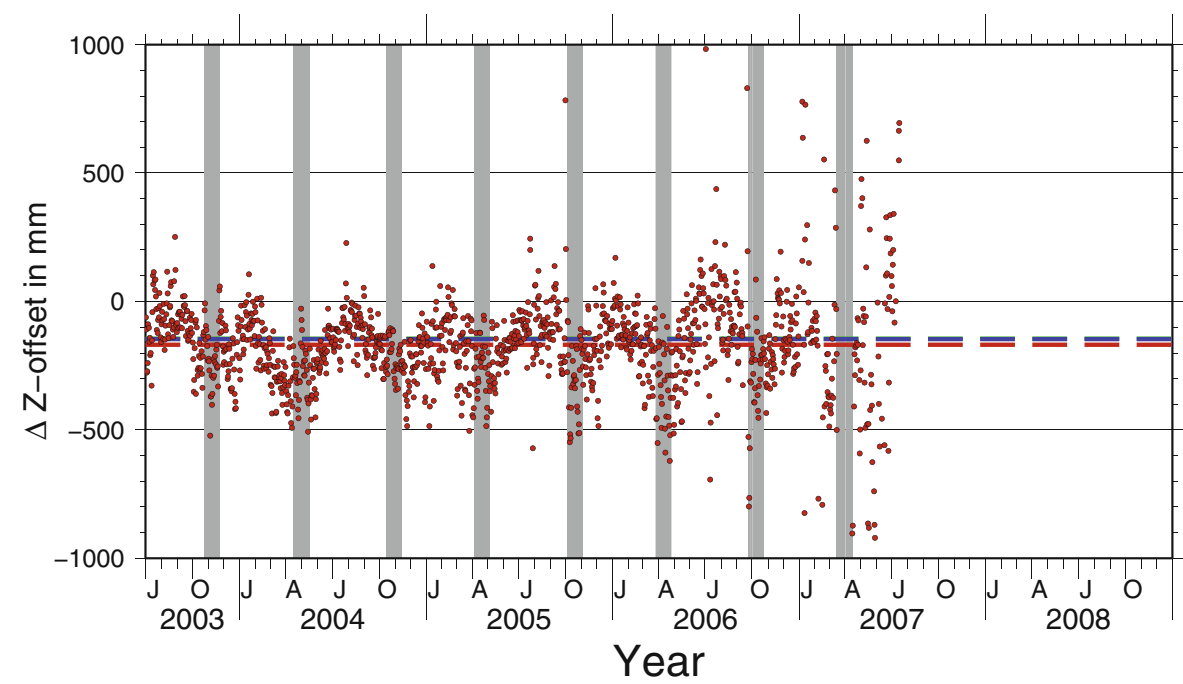

SVN 791/PRN R22 (GLONASS)

Nominal value from igs05.atx for SVN 791

igs05.atx for receivers, GPS and GLONASS

updated PCC for receivers (see Tab. 1), GPS-PCC for GLONASS

updated PCC for receivers (see Tab. 1), GNSS-specific PCC
$2000.9 \mathrm{~mm}$

$1854.4+-10.1 \mathrm{~mm}$

$1832.8+-10.3 \mathrm{~mm}$
$1856.1+-10.1 \mathrm{~mm}$
- Green The original igs05.atx receiver antenna PCC were applied, implying that the GPS-derived values are also used for the GLONASS measurements.

- Blue Updated GPS receiver antenna PCC igs05(upd).atx where applied where available (Table 1), whereas the igs05.atx corrections were introduced for the other antennas. The GPS-derived corrections were used for both the GPS and the GLONASS data.

- Red Updated receiver antenna PCC igs05(upd).atx are used (Table 1). GNSS-specific corrections were applied for the GPS and the GLONASS data.

The three mean $Z$-offsets were estimated using the full covariance information by combining the corresponding normal equations. The stated uncertainty is the standard deviation of the mean offset derived from the time series. The three $Z$-offsets significantly differ by about $150 \mathrm{~mm}$ from the currently used igs 05 .atx value. On the one hand, the two solutions based on GPS-derived receiver antenna corrections for GLONASS ("Green" and "Blue") agree very well. The $Z$-offset emerging from solution "Red" using GNSS-specific corrections, on the other hand, differs by $22 \mathrm{~mm}$ from these two solutions.

Figure 9 gives an overview of the corresponding values for the complete GLONASS constellation active in the time span of 6.5 years, where only satellites observed for at least 90 days are included. The difference of about $20 \mathrm{~mm}$ between using GNSS-specific receiver antenna PCC ("Red") and the other two solutions is approximately the same for all older GLONASS satellites. The difference is smaller for the GLONASS-M satellites. For the youngest satellites, SVN718 up to 726 (SVN716 might also belong to this group, but only few observations were available till summer 2007, because many receivers needed a firmware upgrade to enable tracking of this satellite with frequency channel zero), it even vanishes. These GLONASS-M satellites were launched in 2007 or 2008 when most of the older GLONASS satellites were already inactive. In the same time period, the number of different GNSS receiver antenna types in the tracking network grew. Therefore, either the characteristics of the two satellite antenna types are different or some of the systematic differences between GNSS-specific receiver antenna PCC are absorbed by the satellite antenna $Z$-offsets. Note that the GLONASS tracking network was dominated by two Javad Regant types in the early days, see Fig. 3 (top). A full consistency of the receiver and satellite antenna corrections is, in any case, a requirement to achieve high-quality results.

\section{Update of the satellite antenna PCV}

Using the previously estimated satellite antenna PCO as known, consistent nadir-dependent satellite antenna PCV can now be established. For this purpose, a zero-mean condition was imposed for the estimated PCV of each satellite antenna, which is why corrections for all GPS and GLONASS satellites could be estimated simultaneously.

The nadir-dependent satellite antenna PCV are not sensitive to the three different scenarios for handling the receiver antenna PCC. Therefore, only the most sophisticated solution with GNSS-specific receiver antenna PCC ("Red") is subsequently discussed.

Figure 10 compares the yearly solutions for the nadirdependent satellite antenna PCV as derived from the 


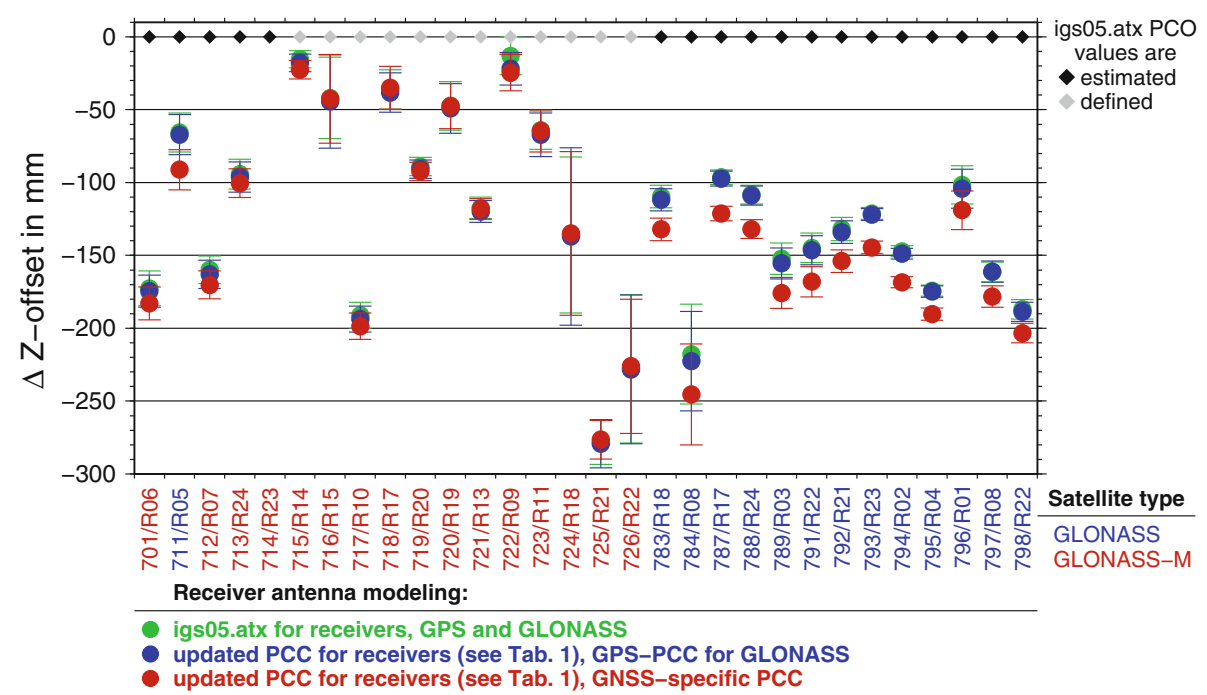

Fig. 9 Differences of the new mean satellite antenna phase center $Z$-offsets for the GLONASS satellites with respect to igs05.atx (diamonds). The receiver antenna phase centers: original igs05.atx corrections (green); igs05(upd).atx with GPS-derived corrections for GLONASS (blue); igs05(upd).atx with GNSS-specific corrections for
GPS and GLONASS observations (red). The error bars indicate the uncertainty of the mean offset as derived from the entire time series of 3-day solutions. (SVN711 is a prototype of the GLONASS-M series; SVN714 outside of the diagram)

Schmid et al. (2007) distinguish three satellite groups of common antenna behavior for the GPS, namely Block II/ IIA, Block IIR-A, and Block IIR-B/IIR-M.

Figure 10 says, however, that the differences of the corrections between individual satellites of a group are small, but significant. This results in the proposal that satellite-specific antenna PCV should be considered for future antenna phase center models. There are, however, two important arguments in favor of the current strategy based on a minimum number of parameters:

- Additional parameters might weaken the normal equation system.

- As each GPS satellite follows the same ground track day after day the station-specific observation geometry is repeated day after day, as well. Therefore, stationspecific effects may cause systematic satellite-specific errors, e.g., errors in the satellite antenna PCV.

The inclusion of observations from Low Earth Orbiting (LEO) satellites might mitigate this problem. As opposed to a terrestrial site, the LEOs track the GNSS satellites more uniformly. Calibration of the space-borne GPS antennas is, on the other hand, a challenging task because of local multipath and cross-talk effects (Jäggi et al. 2009).

The impact of station-dependent effects might, e.g., be studied by comparing satellite-specific PCV derived from solutions using different and independent tracking networks.

The older and the modernized GLONASS satellites obviously show a similar behavior. The scatter of the 

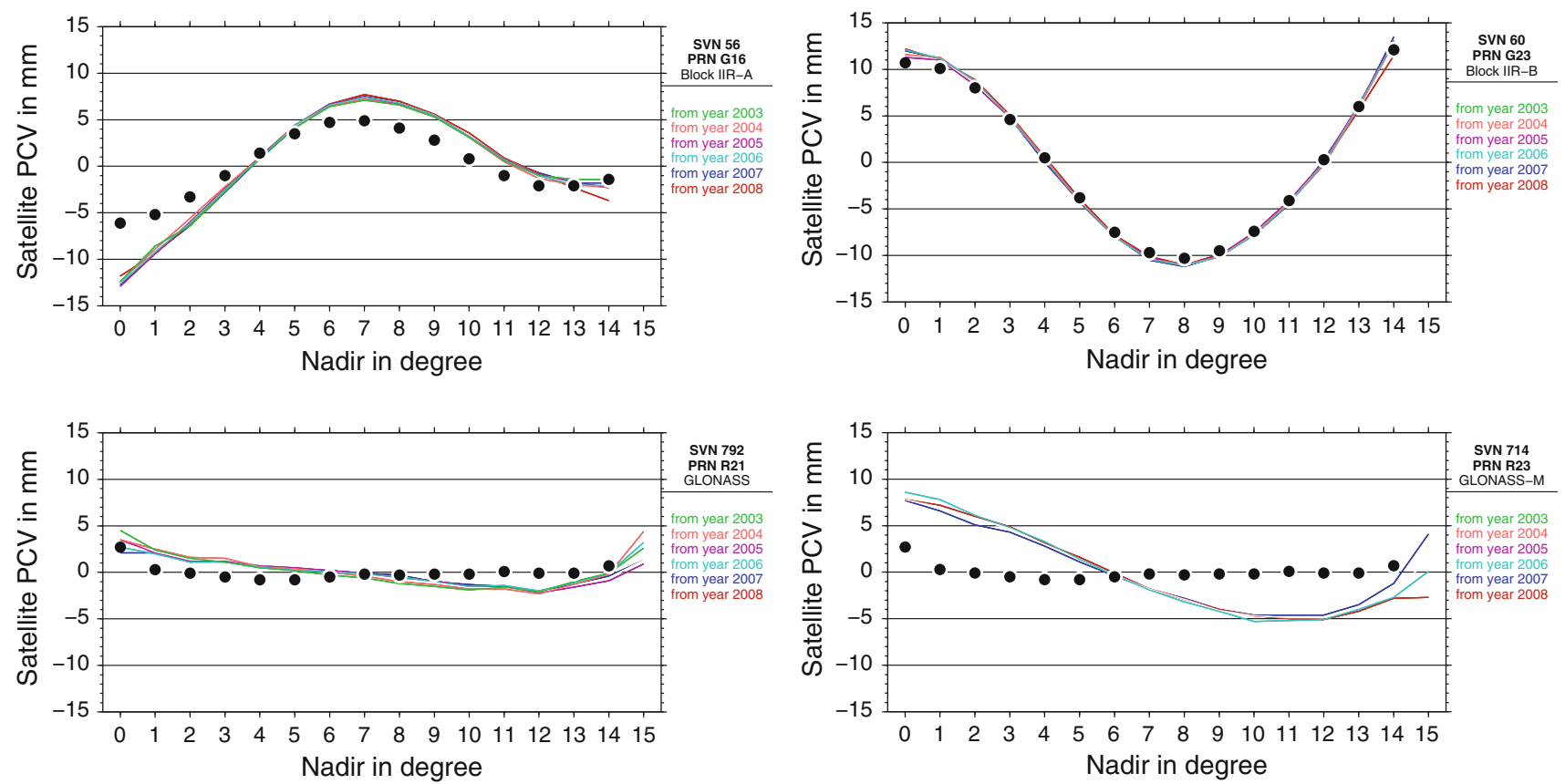

Fig. 10 Examples of yearly solutions for the nadir-dependent satellite antenna PCV for individual GPS (top) and GLONASS (bottom) satellites. The colors refer to the individual yearly solutions. The black dots mark the igs05.atx corrections

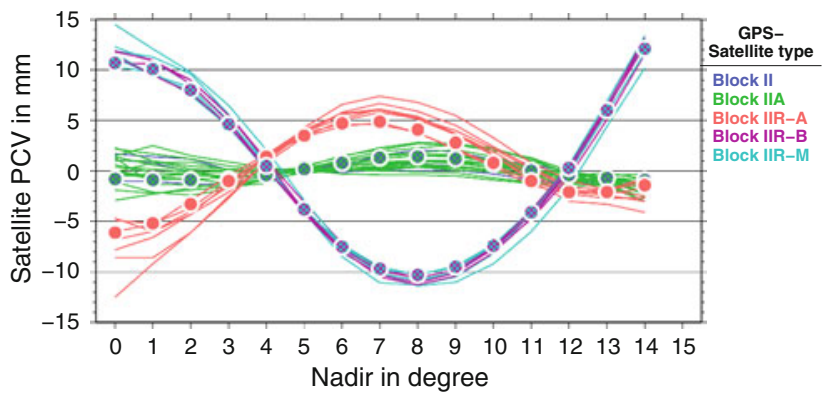

Fig. 11 Nadir-dependent satellite antenna PCV for all GPS (top) and GLONASS (bottom) satellites observed for $>90$ days during the GLONASS extension of the CODE reprocessing. The colors indicate

nadir-dependent GLONASS PCV is comparable to that of the two older generations of GPS satellites (Fig. 11).

The satellite-specific PCV for GLONASS show a similar behavior as in the case of GPS. The scatter between the individual satellites in Fig. 11 is, on one hand, larger than the scatter between the yearly solutions for the individual satellites (see Block II/IIA and Block IIR-A in Fig. 10). On the other hand, the GLONASS satellites are not observed as intensely as the GPS satellites (fewer stations, not well globally distributed). The GLONASS constellation has, however, the advantage that each satellite is observed by the complete tracking network within 17 revolutions corresponding to eight sidereal days. Therefore, the derived GLONASS parameters are less dependent on the tracking network.

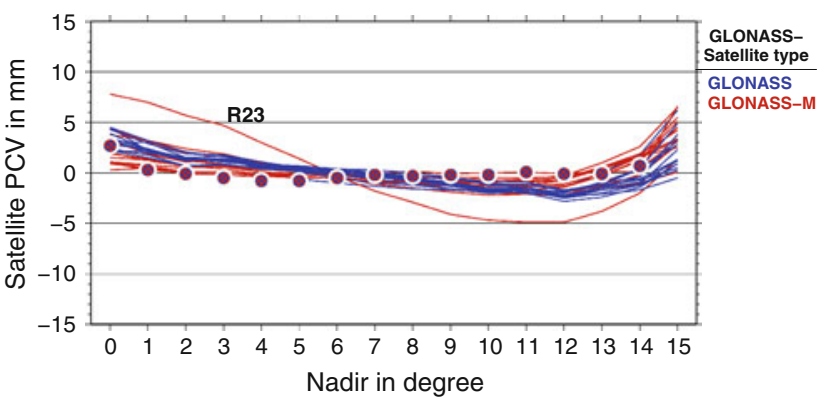

the different satellite types, the dots illustrate the corresponding igs05.atx corrections

One GLONASS-M satellite, namely SVN714, PRN R23, shows a significantly different behavior in the satellite antenna phase center (PCO in Fig. 9 and PCV in Figs. 10, 11). The mean $Z$-offset is, however, only $3 \mathrm{~cm}$ larger than the mean value of all GLONASS-M satellites. As this satellite became active in February 2006, the time slot for computing the corresponding igs05.atx corrections was (in particular in view of the sparse tracking network) not long enough to detect the anomalous behavior of that particular satellite. The assumption that all GLONASS satellites had the same nadir-dependent PCV led to an igs05.atx value for the PCO which was off by about $40 \mathrm{~cm}$. Recently, the value for PRN R23 was corrected (see IGS Mail No.5970). 
Validation of the satellite antenna phase center models

In "Use of GNSS-specific PCC", it was suggested that GNSS-specific receiver antenna PCC should be used as soon as reliable values would become available. The satellite antenna phase center model for the GLONASS satellites was also updated whereas the igs05.atx values for the old GPS satellites were fixed ("Satellite antenna phase center modeling").

To validate these two conclusions, the following solutions have been generated:

- $S_{1}$ The IGS convention for the GPS-derived receiver antenna PCC for GPS and GLONASS measurements is used. The values in the file igs05.atx are used for the satellite antennas.

- $S_{2}$ The GNSS-specific PCC for the receiver antennas igs05(upd).atx (as available in Table 1) and the new satellite antenna PCC are used (derived in "Satellite antenna phase center modeling").

The differences of the results from both solutions are discussed in this section by studying the arc overlaps, the residuals of Satellite Laser Ranging (SLR) measurements, the station coordinates estimated over long time periods, and the results of the kinematic positioning method.

Impact of the updated antenna phase center model on the GLONASS satellite orbits

The orbits of two consecutive days, $i$ and $i+1$ should provide identical positions for each satellite for the midnight epoch $t_{i+1}: \vec{r}_{i}\left(t_{i+1}\right)=\vec{r}_{i+1}\left(t_{i+1}\right)$. The resulting discontinuities $\vec{r}_{i}\left(t_{i+1}\right)-\vec{r}_{i+1}\left(t_{i+1}\right)$ may serve as quality indicators of a particular series of orbits. In an analogous manner, discontinuities may be calculated for the velocity vectors.

The orbits $\vec{r}_{i}(t)$ actually used here for this purpose are those corresponding to the middle day of 3-day arcs, in the way they are generated by the CODE analysis center, see Ineichen et al. (2001). Consecutive 3-day arcs are not independent but they are required because of the poor GLONASS tracking geometry outside Europe.

The differences between the solutions $S_{1}$ and $S_{2}$ at the day boundaries were computed for the position and for the velocity vectors:

$$
\begin{aligned}
\Delta r_{i}= & +\left|\vec{r}_{s_{1}, i}\left(t_{i+1}\right)-\vec{r}_{s_{1}, i+1}\left(t_{i+1}\right)\right| \\
& -\left|\vec{r}_{s_{2}, i}\left(t_{i+1}\right)-\vec{r}_{s_{2}, i+1}\left(t_{i+1}\right)\right| \\
\Delta v_{i}= & +\left|\vec{v}_{s_{1}, i}\left(t_{i+1}\right)-\vec{v}_{s_{1}, i+1}\left(t_{i+1}\right)\right| \\
& -\left|\vec{v}_{s_{2}, i}\left(t_{i+1}\right)-\vec{v}_{s_{2}, i+1}\left(t_{i+1}\right)\right|
\end{aligned}
$$

The differences $\Delta r_{i}$ and $\Delta v_{i}$ are summed up for each satellite over the entire time span of the comparison. The result for the GLONASS satellites is provided in Table 2. A positive sum of differences indicates on the average larger discontinuities for the solution $S_{1}$, implying that the more sophisticated GLONASS antenna phase center model from solution $S_{2}$ is preferable.

The mean position discontinuity per day, averaged over all GLONASS satellites, is only reduced from 63.8 to $63.0 \mathrm{~mm}$ due to the use of updated antenna PCC. For the GLONASS-M satellites, the benefit is even smaller (from 62.8 to $62.4 \mathrm{~mm}$ ). The improvement thus amounts to about $1 \%$ for the complete constellation (from 63.3 to $62.7 \mathrm{~mm}$ ). The benefit is small, but the orbit quality consistently improves for all satellites, except for SVN715.

\section{Validating the GLONASS orbits using SLR data}

The quality of GLONASS orbits may also be validated using the SLR measurements (normal points) provided by the International Laser Ranging Service (ILRS, Pearlman et al. 2002) and the distances between the satellite and the microwave tracking station at the epoch of the SLR measurement. The differences between the two observations are called SLR residuals in this paper. The coordinates of the ILRS sites were taken from the file SLRF2005 (a special reference frame currently used within the ILRS) to generate the residuals for the two sets of GLONASS orbits. Four GLONASS satellites were tracked by ILRS stations in 2008: SVN712/PRN R07 (only from January to May), SVN723/PRN R11 (only from June to December), SVN716/PRN R15, and SVN713/PRN R24 (both throughout the year). Figure 12 shows the mean differences of the absolute values of the residuals between the orbit solutions $S_{1}-S_{2}$.

Most of the mean differences are positive, implying that the residuals were reduced by the updated antenna phase center model. Satellite SVN712 is an exception, showing negative differences for some of the SLR stations, namely 7810 Zimmerwald, 7237 Changchun, and 7090 Yarragadee. Stations located in the vicinity of the three sites do, however, show a different behavior. This is in particular true for Zimmerwald (7810) and Wettzell (8834) (for a few time periods) when tracking SVN712 at the same time. The effect is probably related to station problems, which were not taken into account in our validation procedure, described in Urschl (2007). There was, e.g., no attempt to consider station-specific range biases.

Impact of the updated satellite antenna phase center model on station coordinates

In order to study the impact of the updated satellite antenna PCC on the reference frame, the updated PCC for 
Table 2 Sum of differences according to Eq. 1 at the day boundaries using the IGS standard and the updated satellite antenna PCC from "Satellite antenna phase center modeling", respectively

\begin{tabular}{|c|c|c|c|c|}
\hline \multirow[t]{2}{*}{ PRN } & \multirow[t]{2}{*}{ SVN } & \multirow{2}{*}{$\begin{array}{l}\text { Number of arc } \\
\text { boundaries }\end{array}$} & \multicolumn{2}{|c|}{ Differences in the } \\
\hline & & & Position in $\mathrm{mm}$ & Velocity in $\mathrm{mm} / \mathrm{s}$ \\
\hline R06 & 701 & 1,518 & 944 & 288 \\
\hline R05 & 711 & 979 & 326 & 75 \\
\hline R07 & 712 & 1,263 & 1,350 & 240 \\
\hline R24 & 713 & 929 & 424 & 59 \\
\hline $\mathrm{R} 23$ & 714 & 957 & 1,285 & 197 \\
\hline $\mathrm{R} 14$ & 715 & 684 & 47 & -15 \\
\hline $\mathrm{R} 15$ & 716 & 482 & 97 & 7 \\
\hline $\mathrm{R} 10$ & 717 & 682 & 122 & 47 \\
\hline $\mathrm{R} 20$ & 719 & 407 & 103 & 13 \\
\hline R19 & 720 & 418 & 276 & 27 \\
\hline $\mathrm{R} 18$ & 783 & 1,208 & 671 & 73 \\
\hline R17 & 787 & 1,164 & 658 & 184 \\
\hline R24 & 788 & 827 & 891 & 221 \\
\hline R03 & 789 & 1,428 & 85 & 203 \\
\hline R22 & 791 & 1,399 & 1,644 & 336 \\
\hline R21 & 792 & 1,539 & 2,456 & 343 \\
\hline R23 & 793 & 952 & 871 & 223 \\
\hline R02 & 794 & 1,160 & 680 & 196 \\
\hline R04 & 795 & 1,792 & 1,082 & 264 \\
\hline R01 & 796 & 1,224 & 997 & 238 \\
\hline R08 & 797 & 1,207 & 953 & 163 \\
\hline R19 & 798 & 519 & 448 & 126 \\
\hline
\end{tabular}

Only satellites with at least 400-day boundary values are included. The GLONASS-M satellites are in the upper, the first generation of GLONASS satellites in the lower part

the GLONASS satellites from "Satellite antenna phase center modeling" were used to generate a new set of station coordinates and velocities for the full interval of the GLONASS extension of the CODE reprocessing. The resulting coordinates were compared to the coordinates obtained with the original igs05.atx corrections for the GLONASS satellites. Both solutions were based on the same corrections for the GPS satellites and for the receiver antennas (igs05(upd).atx). The differences between the vertical components of the two solutions are below the 1-mm limit-the horizontal ones are even smaller.

Obviously, the updated GLONASS satellite antenna PCC do not have a significant influence on the coordinates. This is consistent with the findings in "Use of GNSSspecific PCC", where it was already shown that GLONASS has only a small impact on the estimated coordinates. One may also draw the conclusion that the updated satellite antenna corrections do not have a negative impact on the reference frame.
Impact of the updated antenna phase center model on kinematic positioning

Dach et al. (2009) and Ineichen et al. (2008) showed that GLONASS observations used in addition to GPS measurements have a significant impact on coordinates estimated in the rapid-static mode (based on short data spans). One may therefore expect that the coordinates calculated in the kinematic mode are also prone to the use of different phase center models.

The global network was processed with a sampling rate of 30 s over 10 days in December 2008 (days of year 350-359) to study the impact of the antenna phase centers. A few stations representing the antennas with updated PCC (Table 1) on different continents were treated as kinematic. The coordinates of all the remaining stations, the satellite orbits, and the Earth rotation parameters were introduced as known values from the daily processing of the static network.

Approximately 28,800 positions for each of the kinematic stations were assigned to adjacent subintervals with lengths of either 15 or $60 \mathrm{~min}$. The 30 or 120 positions within each interval were used to compute the standard deviation of the mean values of the coordinates. The arithmetic mean of the standard deviations from all 960 or 240 intervals is provided in Table 3 . Four sets of solutions (experiments) are discussed subsequently. The first set is represented by columns 4 and 5 , the second by columns 6 , 7 , and 8 , the third by columns 9 and 10 , and the fourth by columns 11 and 12 .

The first set of solutions in Table 3, based on 15-min intervals, compares the GPS-only and the combined GPS/ GLONASS solution applying identical receiver antenna PCC for the GPS and GLONASS measurements-corresponding to current practice in the IGS. Despite this deficiency, the standard deviation of the mean station height for intervals of $15 \mathrm{~min}$ is improved. 32-GPS and 16-GLONASS satellites were active in December 2008. Assuming a white noise law, one would expect an improvement by a factor of $\sqrt{1.5} \approx 1.22$ due to the additional GLONASS observations. This value was achieved for many of the analyzed sites.

The updated GNSS-specific receiver antenna PCC model igs05(upd).atx was used for a second set of solutions, also based on 15-min intervals. The GPS-only and the combined GPS/GLONASS solution (first two solutions of the second set) are compared as in the previous experiment and the results are the same. The third of the second set of solutions used the updated satellite antenna PCC from "Satellite antenna phase center modeling" for the GLONASS satellites and was based on a combination of GPS and GLONASS. Compared to the solution using the IGS satellite antenna PCC, the differences are $<0.1 \mathrm{~mm}$. 


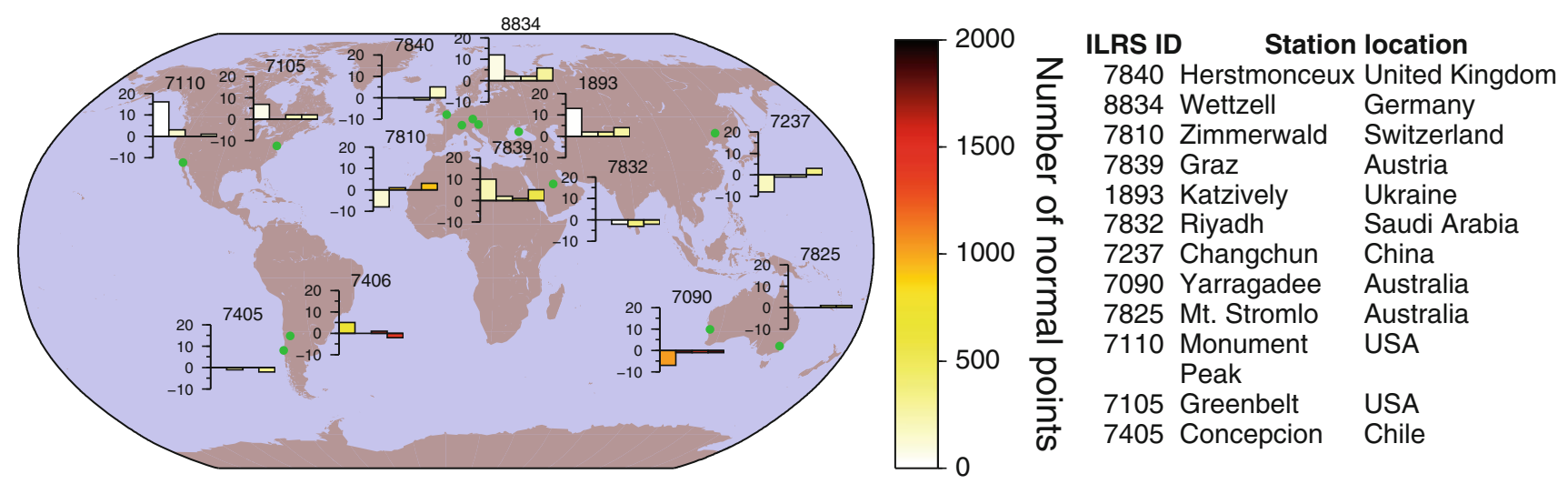

Fig. 12 Mean differences of the absolute values of the SLR residuals between the 3-day GLONASS orbits computed with original igs05.atx or updated antenna PCC (Table 1; "Satellite antenna phase center modeling") in mm. Only SLR stations (green dots) with at least 400 normal points in 2008 were included. The four bars per tracking station indicate the residual differences for the GLONASS satellites 712 (PRN R07), 723 (PRN R11), 716 (PRN R15), and 713 (PRN R24), respectively. The colors of the bars indicate the number of normal points contributing to this statistics
This result could be expected, because the satellite geometry does not change substantially during the 15-min intervals. The antenna phase center model, therefore, has only a systematic influence on the mean value of a rapidstatic solution, but does not show up in the standard deviation of the mean coordinates.

The third set of solutions in Table 3 is based on GLONASS-only. The impact of the updated antenna PCC on the standard deviations of the coordinates is slightly larger than in the combined case. It is, on one hand, remarkable that a rapid-static solution is at all possible with the limited number of active GLONASS satellites (16 December 2008). The noise of these solutions is, on the other hand and not unexpectedly, larger than the corresponding noise of the GPS-only solution, in particular for stations with a weak satellite geometry during a significant part of the day (e.g., CONZ and REUN).

As the effect of the antenna PCC on the 15-min solutions is limited, the fourth set of solutions (corresponding to the last two columns in Table 3 ) are fictitious 60-min coordinate solutions. As the satellite geometry changes significantly within $60 \mathrm{~min}$, the antenna phase center model should have more influence on the standard deviations of the hourly solutions. Two GLONASS-only solutions are compared in Table 3 both using the GLONASS-specific receiver antenna PCC from igs05(upd).atx. The first solution uses the igs05.atx GLONASS satellite antenna corrections, the second one the updated values provided in "Satellite antenna phase center modeling". A small benefit of using the improved antenna phase center model results in the case of the 60-min solution (10 stations have smaller, 5 larger standard deviations, and 7 are on the same level). Note that other effects like near-field multipath also have an impact on these values. Such site-specific issues play a more important role for the 60-min solutions because of the reduced redundancy of the kinematic GLONASS-only solution when compared with GPS-only (double number of satellites) or a combined GPS/GLONASS (triple number of satellites) solution.

For the latter two GLONASS-only solutions, the variations of the fictitious hourly solutions were analyzed. For this purpose, the mean coordinates for intervals of $60 \mathrm{~min}$ were extracted from the kinematic solutions. The RMS of these time series of hourly coordinates is shown in Table 4. The updated satellite antenna PCC-only cause a minor impact on the hourly coordinate solutions (excluding the stations CONZ and REUN, the mean of the RMS values of all stations is identical on the sub-mm level). This confirms the conclusions drawn from Table 3 and in "Impact of the updated satellite antenna phase center model on station coordinates" that the updated satellite antenna phase center model for the GLONASS satellites does not "disturb" the coordinate solution. The solution is dominated by environmental effects, which are difficult to be eliminated in the case of a GLONASS-only solution due to the small redundancy.

\section{Summary and conclusions}

The CODE reprocessing solution for the IGS based on GPS-only, performed at the Technische Universität München, has been expanded to a combined GPS/GLONASS solution for the time period from May 2003 to December 2008. Due to improved modeling and additional tracking sites, the GLONASS orbits could be improved by up to a factor of about two compared to the operational solution (in particular prior to 2007) achieved by the CODE Analysis 


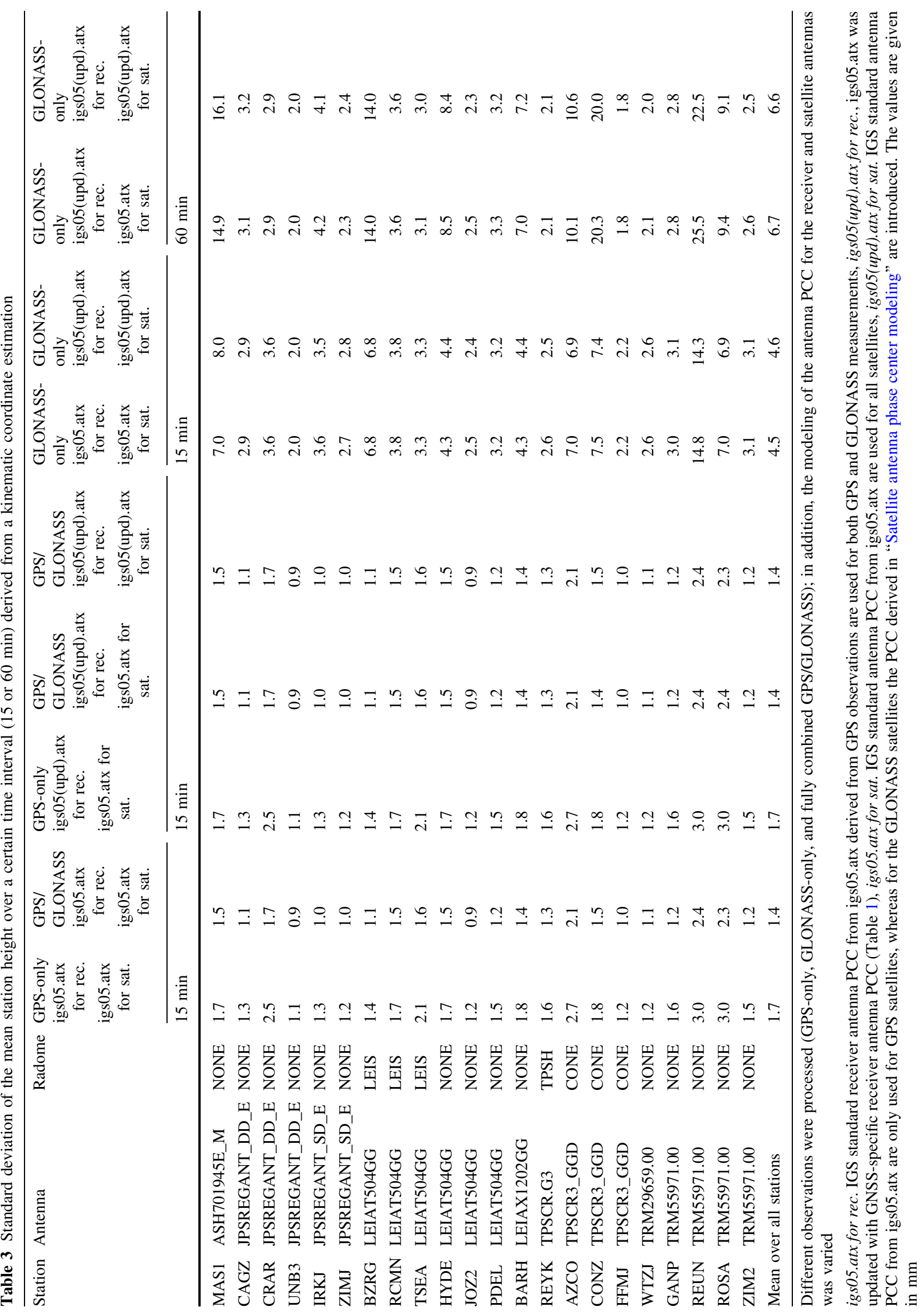


Table 4 RMS of the hourly mean coordinates derived from a kinematic positioning considering only GLONASS measurements

\begin{tabular}{|c|c|c|c|c|c|c|}
\hline \multirow[t]{2}{*}{ Station } & \multicolumn{3}{|c|}{$\begin{array}{l}\text { GLONASS-only } \\
\text { igs05(upd).atx for rec. } \\
\text { igs05.atx for sat. }\end{array}$} & \multicolumn{3}{|c|}{$\begin{array}{l}\text { GLONASS-only } \\
\text { igs05(upd).atx for rec. } \\
\text { igs05(upd).atx for sat. }\end{array}$} \\
\hline & North & East & Up & North & East & Up \\
\hline MAS1 & 1.2 & 5.6 & 6.2 & 0.5 & 5.1 & 6.4 \\
\hline CAGZ & 5.2 & 12.7 & 0.8 & 4.7 & 12.3 & 0.6 \\
\hline CRAR & 0.7 & 1.1 & 0.7 & 0.6 & 1.4 & 0.0 \\
\hline UNB3 & 0.7 & 0.0 & 0.8 & 0.4 & 0.0 & 0.6 \\
\hline IRKJ & 5.5 & 1.5 & 5.4 & 5.4 & 3.3 & 5.8 \\
\hline ZIMJ & 0.0 & 0.0 & 0.3 & 0.1 & 0.0 & 0.1 \\
\hline BZRG & 1.2 & 3.9 & 3.4 & 1.3 & 4.5 & 3.7 \\
\hline RCMN & 1.7 & 3.7 & 2.0 & 1.6 & 3.7 & 2.0 \\
\hline TSEA & 2.9 & 3.0 & 6.2 & 3.5 & 1.5 & 6.8 \\
\hline HYDE & 1.3 & 4.7 & 16.5 & 3.5 & 5.2 & 19.4 \\
\hline JOZ2 & 0.5 & 0.8 & 0.9 & 0.5 & 0.6 & 0.9 \\
\hline PDEL & 0.6 & 3.1 & 7.5 & 0.6 & 3.0 & 7.6 \\
\hline BARH & 1.8 & 0.3 & 0.2 & 1.6 & 0.6 & 1.3 \\
\hline REYK & 0.1 & 0.8 & 0.9 & 0.1 & 0.8 & 0.6 \\
\hline AZCO & 4.0 & 1.0 & 28.6 & 3.1 & 1.1 & 27.3 \\
\hline $\mathrm{CONZ}$ & 66.5 & 185.4 & 125.7 & 61.3 & 184.8 & 99.8 \\
\hline FFMJ & 0.4 & 0.8 & 0.7 & 0.5 & 0.7 & 0.5 \\
\hline WTZJ & 0.5 & 0.7 & 2.0 & 0.5 & 0.7 & 2.0 \\
\hline GANP & 0.7 & 0.1 & 3.6 & 0.7 & 0.0 & 3.6 \\
\hline REUN & 27.4 & 104.8 & 105.5 & 27.8 & 114.5 & 101.2 \\
\hline ROSA & 7.6 & 2.9 & 1.9 & 7.7 & 2.4 & 1.6 \\
\hline ZIM2 & 0.0 & 0.1 & 0.2 & 0.1 & 0.0 & 0.1 \\
\hline Mean & 6.2 & 15.9 & 15.6 & 6.0 & 16.4 & 14.2 \\
\hline
\end{tabular}

Different satellite antenna phase center models were applied (descriptions of the solution IDs are given in Table 3). The values are given in $\mathrm{mm}$

Center. The time series of combined GPS/GLONASS solutions was used as the basis for this study and to update the antenna phase center model.

An updated antenna PCC file, called igs05(upd).atx, was generated containing all receiver antenna/radome combinations available with reliable GNSS-specific corrections. Some converted field calibrations could be replaced by robot calibrations in the updated file. These updated corrections affect the station coordinates by up to $5 \mathrm{~mm}$, even if the GPS-derived values are used for both, the GPS and the GLONASS observations. This result underlines the problem of a stable reference frame realization on one hand and the necessity to update the receiver antenna PCC on the other hand.

GNSS-specific receiver antenna corrections became available for many antenna types since 2005/06. The differences between GPS and GLONASS PCV reach values of up to $10 \mathrm{~mm}$ for the ionosphere-free linear combination.
The introduction of these GNSS-specific corrections has a systematic impact of only up to $1 \mathrm{~mm}$ on the estimated station coordinates in a multi-year solution. In some cases, the GLONASS-specific "type-mean" values show larger uncertainties than the GPS-specific values, because of the smaller number of calibrated antennas. As soon as the uncertainty is small enough, the GNSS-specific corrections should be used, because the impact of GLONASS on a combined GPS/GLONASS solution currently grows from month to month thanks to the continuous growth of the multi-GNSS tracking sites in the global IGS network and thanks to the growing number of GLONASS satellites. The differences between GPS- and GLONASS-specific receiver antenna PCV are typically twice as large as the difference between igs05.atx values and the updated receiver antenna PCC for GPS. The latter differences caused 5-mm changes in the estimated station heights.

An update of the currently used GNSS satellite antenna phase center model is also necessary for at least formal reasons. More or less the complete GLONASS constellation has been replaced since the computation of the currently used igs05.atx values. The GLONASS tracking situation has, moreover, dramatically improved since that time. Today, the uncertainties of the GLONASS satellite antenna corrections, as documented here, are comparable to those of the GPS satellites.

Some satellite antennas show significant deviations from the nadir-dependent block-specific PCV. Examples for both GPS and GLONASS satellites were provided. Exceptions from the block-specific PCC should therefore be allowed for specific satellites. Satellite-specific corrections should be considered for future satellite antenna phase center models.

The updated satellite antenna phase center model does not degrade the reference frame of combined GPS/ GLONASS solutions. GLONASS-only rapid-static or kinematic solutions benefit most from the updated satellite antenna corrections. The new coefficients will be provided as a contribution to the next generation of standard IGS antenna PCC.

\section{References}

Altamimi Z, Collilieux X, Legrand J, Garayt B, Boucher C (2007) ITRF2005: a new release of the International Terrestrial Reference Frame based on time series of station positions and earth orientation parameters. J Geophys Res 112(B9):401-419. doi:10.1029/2007JB004949

Beutler G, Brockmann E, Gurtner W, Hugentobler U, Mervart L, Rothacher M, Verdun A (1994) Extended orbit modeling techniques at the CODE processing center of the International GPS Service for Geodynamics (IGS): theory and initial results. Manuscr Geod 19(6):367-386 
Dach R, Hugentobler U, Fridez P, Meindl M (eds) (2007) Bernese GPS Software Version 5.0. Astronomical Institute, University of Bern, Switzerland

Dach R, Brockmann E, Schaer S, Beutler G, Meindl M, Prange L, Bock H, Jäggi A, Ostini L (2009) GNSS processing at CODE: status report. J Geod 83(3-4):353-365. doi:10.1007/s00190-0080281-2

Dow J, Neilan R, Rizos C (2009) The International GNSS Service in a changing landscape of Global Navigation Satellite Systems. J Geod 83(3-4):191-198. doi:10.1007/s00190-008-0300-3

Ineichen D, Springer T, Beutler G (2001) Combined processing of the IGS and the IGEX network. J Geod 75(11):575-586. doi: $10.1007 / \mathrm{s} 001900000152$

Ineichen D, Brockmann E, Schaer S (2008) Processing combined GPS/GLONASS data at swisstopo's local analysis center. In: Ihde J, Hornik $\mathrm{H}$ (eds) Proceedings of EUREF Symposium, 18-20 June 2008, Brussels, Belgium, EUREF Publication, No.18 (in press)

Jäggi A, Dach R, Montenbruck O, Hugentobler U, Bock H, Beutler G (2009) Phase center modeling for LEO GPS receiver antennas and its impact on precise orbit determination. J Geod 83(12):1145-1162. doi:10.1007/s00190-009-0333-2

Ostini L, Dach R, Meindl M, Schaer S, Hugentobler U (2008) FODITS: a new tool of the Bernese GPS Software. In: Inde J, Hornik H (eds) Proceedings of EUREF Symposium, 18-20 June 2008, Brussels, Belgium, EUREF Publication, No.18 (in press)
Pearlman M, Degnan J, Bosworth J (2002) The international laser ranging service. Adv Space Res 30(2):135-143. doi:10.1016/ S0273-1177(02)00277-6

Schaer S, Brockmann E, Ineichen D (2009) Inclusion of GLONASS for EPN analysis at CODE/swisstopo. In Torres J, Hornik $\mathrm{H}$ (eds) Proceedings of EUREF Symposium, 4-6 June 2007, London, United Kingdom, EUREF Publication, No. 17, pp 8694. ISBN 978-3-89888-916-2

Schmid R, Steigenberger P, Gendt G, Ge M, Rothacher M (2007) Generation of a consistent absolute phase center correction model for GPS receiver and satellite antennas. J Geod 81(12):781-798. doi:10.1007/s00190-007-0148-y

Steigenberger P, Schaer S, Lutz S, Dach R, Ostini L, Hugentobler U, Bock H, Jäggi A, Meindl M, Thaller D (2009) CODE contribution to IGS reprocessing: status and perspectives. Presented at EGU General Assembly, 19-24 April 2009, Vienna, Austria

Urschl C (2007) Center for Orbit Determination in Europe (CODE) Associate Analysis Center. In: Noll C, Pearlman M (eds) Proceedings of International Laser Ranging Service 2005-2006 Report, NASA/TP-2007-214153, pp 12/19-12/20

Wübbena G, Schmitz M, Boettcher G, Schumann C (2006) Absolute GNSS antenna calibration with a robot: repeatability of phase variations, calibration of GLONASS and determination of carrier-to-noise pattern. In: Springer T, Gendt G, Dow J (eds) Proceedings of International GNSS Service: Analysis Center workshop, 8-12 May 2006, Darmstadt, Germany 